\title{
Loss Minimization by Reconfiguration along with Distributed Generator Placement at Radial Distribution System with Hybrid Optimization Techniques
}

\author{
Rafi Vempalle $^{1}$ (D) P.K. Dhal ${ }^{1}$ \\ Received: 18 November 2019 / Accepted: 22 July 2020 / Published online: 7 September 2020 \\ (C) Springer Nature Singapore Pte Ltd. 2020
}

\begin{abstract}
In this paper a new methodology is used to reconfigure the topology of distribution system and placement of Distributed generators (DG) optimally. This methodology is adopted from the three optimization techniques which are Genetic Algorithm (GA), Particle Swarm Optimization (PSO) and Blue Whale Optimization (BWO). The basic principles of the GA is used the optimal switching, the foundation for the swarm searching techniques, PSO is used to find the optimal placement and latest optimization technique, BWO is used to find the size of the type-III DG. The major objective of the paper is to minimize the losses through optimal reconfiguration and optimal placement of DG in balanced radial distribution system.
\end{abstract}

Keywords BIBC Matrix · Distributed generator - Distribution system · IEEE 33 and 69-bus test system - PSO-BWO . Reconfiguration

\section{Introduction}

The increase of the global warming, mandate the researchers to look for the other alternative for generating the electric power. But, the generation of electric power through renewable sources cannot meet the required demand of the power system. So generators are erected at the consumer side which are called distributed generators, designed using PV systems, wind turbines etc. Power system is the combination generation, transmission and distribution. Distribution system is the tail end which supplies the electrical power to the consumers. The demand of electricity is rising day-to-day. The increasing of electrical demand is due to rise of population and the people customizing their needs towards the luxuries. To meet with the increasing load with existing resources is more complicated issue. By the increasing usage of conventional sources like coal

Rafi Vempalle

vempallerafi@gmail.com

P.K. Dhal

pradyumna.dhal@ rediffmail.com

1 Department of EEE, Vel Tech Rangarajan Dr.Sagunthala R\&D Institute of Science and Technology, Chennai, India and crude oil the pollution increasing day to day as well. The contribution of the losses from generation to transmission and transmission to distribution are also high. The vain of reducing the losses at the mentioned systems are also reduced the usage of conventional fuels. By optimal placing of compensating devices at the transmission and distribution system will meet the goal of reducing the losses to great extent. But the erection and maintenance cost of compensating devices are also so complex. Mew E. Baran and Felix F. Wu [1] introduced the concept of reconfiguration of distribution system at their paper on 1989. They introduced the terminology of tie switches to change the structure of the radial distribution system for maintaining the load balancing throughout the system. M. M. A. Salama, A. Y. Chikhani [2] proposed an approach of VAR control to trouble shoot the radial distribution system problem. The VAr control at every branch can control the reactive power flow which will impact the node voltages. T. P. Wagner et.al [3] proposes the application of distribution automation for feeder reconfiguration. The feeder reconfiguration will reduce the power losses with distribution automation that will improve the voltage profile of the system. T. H. Chen et al. [4] proposed a novel approach distribution load flow studies which is very rigid to analyze both balanced and unbalanced systems. S. Ghosh and K. S. Sherpa [5] detailed a new approach of load flow for analyzing the losses in system. The method is successfully 
implemented to both balanced and unbalanced radial nature. Ola Badran et al. [6] detailed a complete review reconfiguration of distribution system along with distributed generators. The optimal location distributed generators along with reconfiguration of distribution systems will make the system more reliable with lesser losses. Dong-Li Duan et al. [7] proposed a methodology a enhanced genetic algorithm for reconfiguring of distribution system. They detailed the remarkable changes in classical genetic algorithm called enhanced genetic algorithm and adopted to one of the power system problems. A venkata sudhakar Reddy et al. [8] proposed the method of reconfiguration system with PSO. But in this paper the load balancing was not maintained properly, with these losses are not reduced great percentages. M. Damodar Reddy et al. [9] published the paper on reconfiguration on distribution system by using grey wolf algorithm. The paper covers the adaptation of reconfiguration problem to the latest optimization technique. But the load balancing throughout the feeder cannot achieve. The efficient optimization technique called whale optimization technique is proposed by D. Prakash [10] for optimal placing of capacitors in radial distribution networks. The comparative study of DGs are proposed in [11]. The real power compensation DGs are designed with PV system which are designed with inverter [12]. The optimal placement and sizing of DG in radial distribution system is needed to reduce the losses in the system [13]. The increase in losses of the system will affect the bus voltage of the system, which motivates the usage of voltage regulation through energy storage system [14]. The different load models of the distributions is studied and optimal placement of DG is proposed with different optimizing techniques [15]. The literature detailed up to now is illustrated only one heuristic optimization techniques for reconfiguration, placement and sizing of DG. In this paper different optimization algorithms such as GA for reconfiguration, PSO for placement of DG and BWO for Sizing of the DG. The paper is divided in to four sections, such as second section load flow is detailed, section three distribution system reconfiguration is discussed and section four comparative analysis of different optimization techniques is proposed and section five results are detailed with conclusions.

\section{Distribution Load Flow}

The analysis of distribution network is starting by determining its node voltages and distribution losses using load flow studies. Majority of the researchers in the literature are strongly recommended the backward-forward sweep method for balanced radial distribution systems power flow analysis. The line currents are calculated at backward stream using Kirchhoff's current law $(\mathrm{KCL})$ and the node voltages are calculated at forward stream using Kirchhoff's Voltage law(KVL). The equations that are used in for calculating power losses, branch currents and node voltages are shown below which is explained with sample 6 bus and five branch radial distribution system.

$S_{L, n}=P_{L, n}+j Q_{L, n}=V_{n} \cdot I_{L, n}{ }^{*}$

The load current at any node is given by

$I_{L, n}=\left(\frac{P_{L, n}+j Q_{L, n}}{V_{n}}\right)^{*}=\frac{P_{L, n}-j Q_{L, n}}{V_{n}{ }^{*}}$

Where, $P_{L, n}, Q_{L, n}$ and $V_{n}$ are the active power demand, reactive power demand, the voltage magnitude at load bus respectively.

\section{Formation of Bus Injection to Branch Current (BIBC) Matrix}

The current equations can be found by using KCL for Fig. 1 is given as

$I_{B 5}=I_{L 6}$

$I_{B 4}=I_{L 5}$

$I_{B 3}=I_{L 4}+I_{L 5}$

$I_{B 2}=I_{L 3}+I_{L 4}+I_{L 5}+I_{L 6}$

$I_{B 1}=I_{L 2}+I_{L 3}+I_{L 4}+I_{L 5}+I_{L 6}$

Thus, the correlation among load currents \& line currents in matrix structure as

$\left[I_{B}\right]=[B I B C]\left[I_{L}\right]$

The receiving end voltages can be premeditated by forward sweep as

$V_{q}(k)=V_{p}(k)-I_{B}(k) * Z_{B}(k)$

\section{Total System Real Power Losses}

The total real power loss in a distribution system can be conveyed as

$P_{L, T}=\sum_{k=1}^{B} I_{k}^{2} \cdot R_{k}$

\section{Network Reconfiguration}

Network reconfiguration is the process of changing the radial structure of the distribution system to reduce the losses for improving voltage profile. The no of tie switches in a distribution system depends upon the no of loops by closing the tie switches. The different combination tie switches along with 
Fig. 1 A Sample 6-node radial distribution system

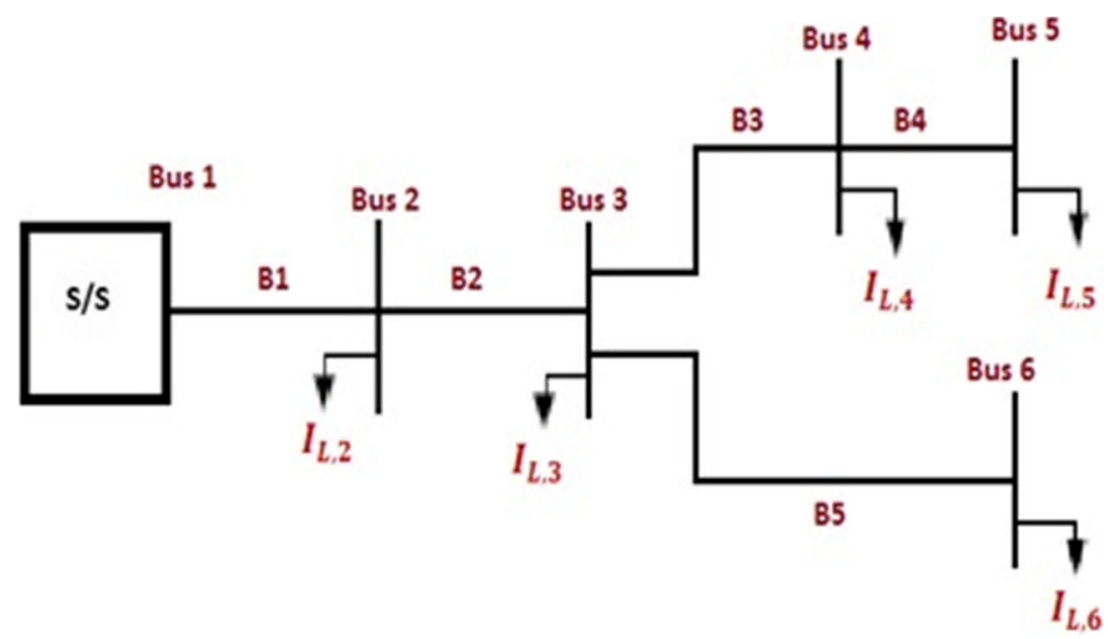

main branches will make the system more reliable for reducing the losses and improving the voltage profile.

The following table will give the no possible loops in standard 33 node radial distribution system (Fig. 2).

The Table 1 shows the loop formation with the tie line switches combination. The selection of suitable location of tie line switches will make the radial distribution system with load balancing. Since all the nodes are not loaded with constant. So the selection of suitable location of tie line switches is more important. The complexity in selection of tie line switches for small radial distribution system might be lesser where as for practical radial distribution system which is higher nodes; selection of tie line switches is seditious task. By implementing this power system problem to the heuristic optimization techniques the selection of the tie line switches might become very easy. The further sections will give a detailed explanation, on adoption of reconfiguration problem to the heuristic algorithms like GA, PSO, and BWO.

\section{Placement of Distributed Generators (DG)}

The distributed generators are one of the compensating devices for reducing the losses of radial distribution system.
The major advantage of DGs over capacitors is that it can compensate both real and reactive power. By considering this aspect, DGs are divided into three types:

1. Type-1 DG: compensates both real and reactive power.

2. Type-2 DG: compensates only reactive power.

3. Type-3 DG: compensates only real power.

The scope of the paper is upto type-1 DG. Type -1 DG can be erected with the help of renewable sources like wind, tide etc.

The minimization of the losses is the objective of this paper, by using hybrid optimization techniques, which is designed by using DA-PSO. In this, DA is used to find the optimal switching combination and PSO is used to find the suitable location and size of the DG with combined objective of minimizing the losses.

$$
\begin{array}{ll} 
& f_{o b j}=\min (\text { Loss }) \\
& V_{\min }(p . u) \leq V \leq V_{\max }(p . u) \\
\text { subject to } & w_{\text {here }} \\
& V_{\min }=0.95 \\
& V_{\min }=1.05
\end{array}
$$

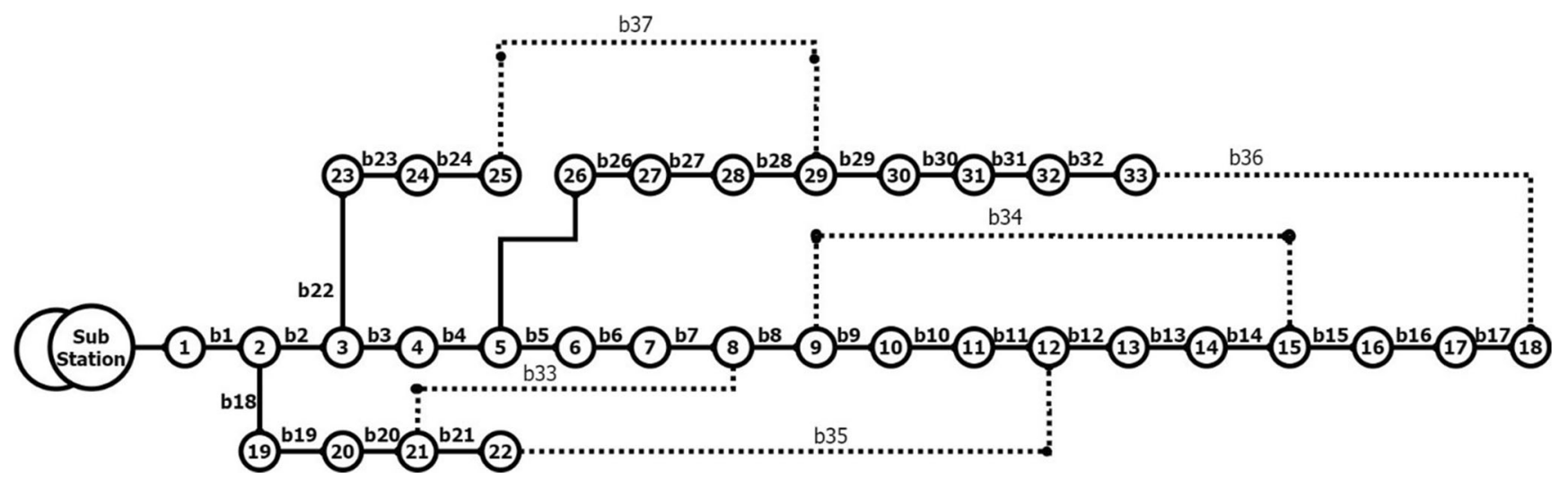

Fig. 2 IEEE-33 node Radial Distribution system along with Tie line switches 
Table 1 Loops of 33 radial distribution system with five tie line switches

\begin{tabular}{llllll}
\hline Node.No & Loop1 & Loop2 & Loop3 & Loop4 & Loop5 \\
\hline 1 & 3 & 2 & 8 & 8 & 9 \\
2 & 4 & 3 & 9 & 9 & 10 \\
3 & 5 & 4 & 15 & 10 & 11 \\
4 & 6 & 5 & 16 & 11 & 12 \\
5 & 26 & 6 & 17 & 12 & 13 \\
6 & 27 & 7 & 18 & 22 & 14 \\
7 & 28 & 8 & 33 & 21 & 15 \\
8 & 29 & 21 & 32 & & \\
9 & 25 & 20 & 31 & & \\
10 & 24 & 19 & 30 & & \\
11 & 23 & & 29 & & \\
12 & & & 28 & & \\
13 & & & 27 & & \\
14 & & & 26 & & \\
15 & & & 6 & & \\
16 & & & 7 & & \\
\hline
\end{tabular}

The algorithm for the proposed methodology is given as follows

Step 1: Initialize the particles with bus numbers with $\mathrm{X}$ (1, i) = Randi (1, nswitches).

$X=\left[\begin{array}{ccccccc}x_{11} & x_{12} & x_{13} & x_{14} & x_{15} & - & - \\ x_{21} & x_{22} & x_{23} & x_{24} & x_{25} & - & - \\ - & - & - & - & - & - & - \\ - & - & - & - & - & - & - \\ x_{n p 1} & x_{n p 2} & x_{n p 3} & x_{n p 4} & x_{n p 5} & - & -\end{array}\right]$

Step 2: Initialize the maximum inertia $\mathrm{W}_{\max }$, minimum inertia $\mathrm{W}_{\text {min., }} \mathrm{C}_{1}, \mathrm{C}_{2}$, number of generations $\mathrm{ng}$ and number of particles np

Step 3: Calculate the losses for every particle by using load flow analysis for every generation.

Step 4: Investigate the minimum losses at every generation
Fig. 3 Flow chart of the proposed algorithm

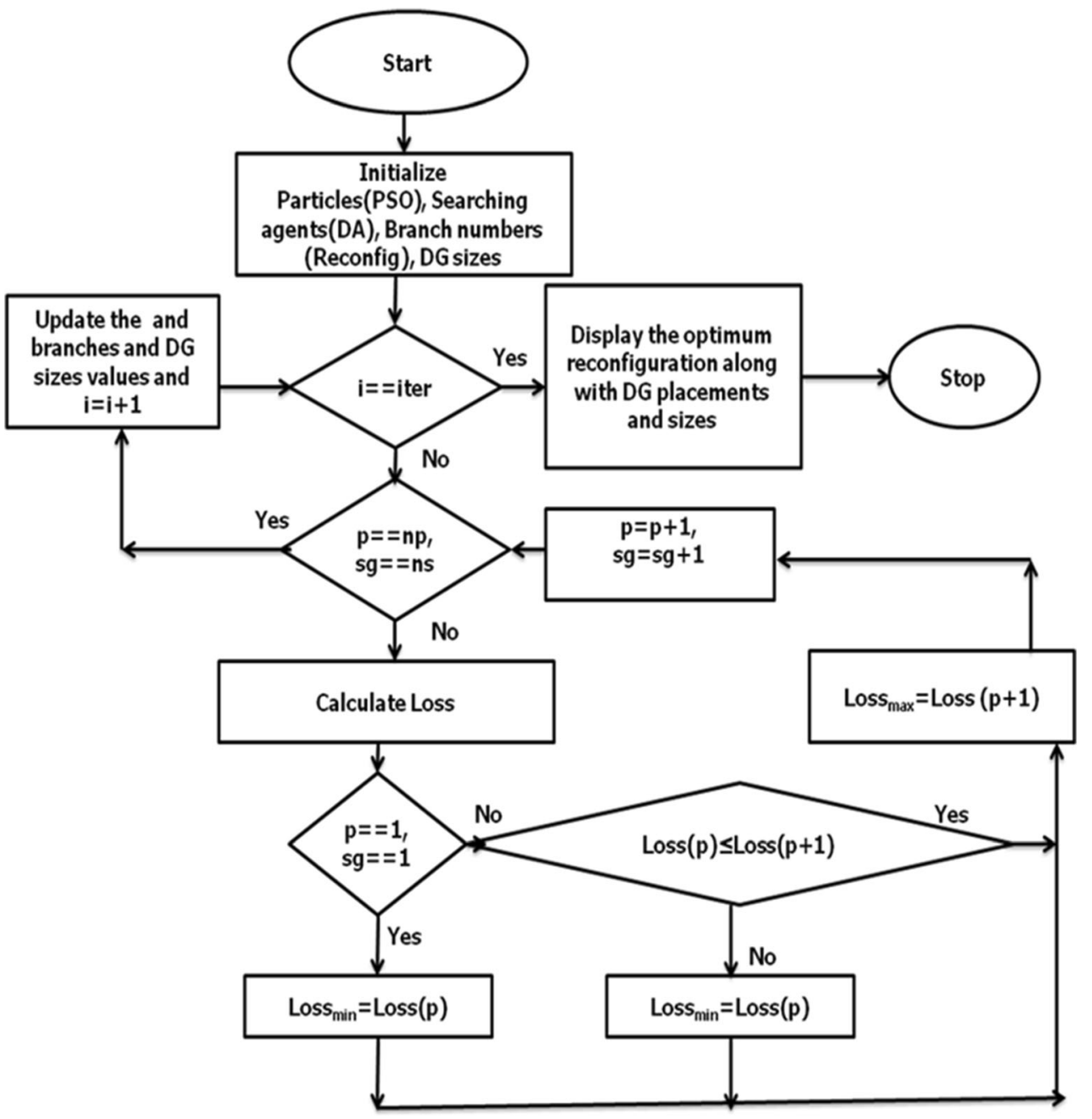




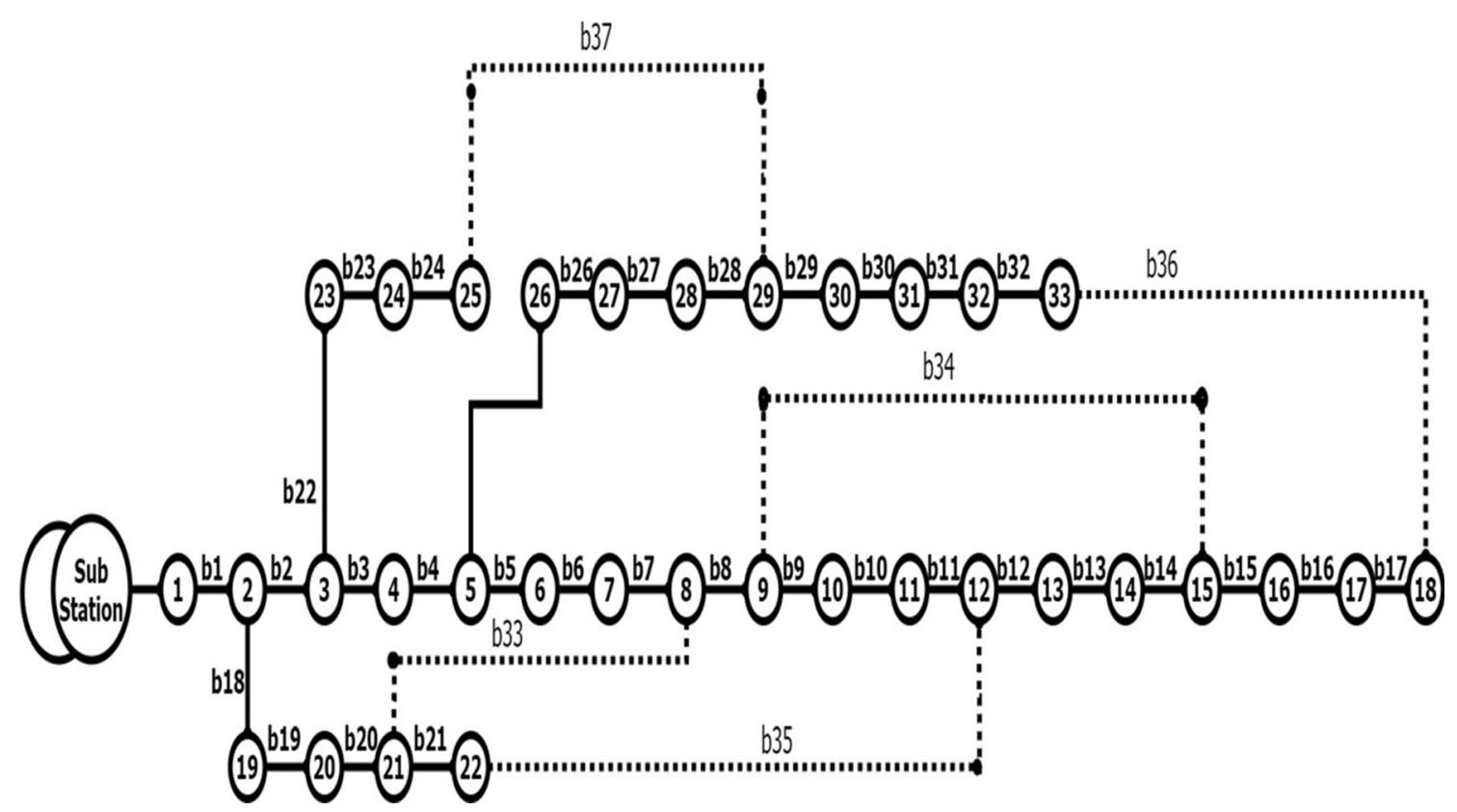

Fig. 4 Single line diagram of IEEE 33 bus radial distribution system

Step 5: Update the particles with the following eq.

$\mathrm{X}(\mathrm{Update})=\mathrm{W} * \mathrm{X}+\mathrm{C}_{1} * \operatorname{rand}(1) *(\mathrm{Pbest}-\mathrm{X})+$ $\mathrm{C}_{2} * \operatorname{rand}(1) *($ Gbest $-\mathrm{X})$

Where $\quad W=W_{\max }-\frac{\left(W_{\max }-W_{\min }\right)}{(n g-1)} \times($ iter -1$)$

Step 6: Adjust update positions with minimum and maximum constraints.

Step 7: Repeat the Step 3 to step 6 for all generations.

Step 8: Initialize the searching agents with bus numbers with $\mathrm{X}(1, \mathrm{i})=$ Randi $(2$, nbus $)$.

$X=\left[\begin{array}{cc}x_{11} & x_{12} \\ x_{21} & x_{22} \\ - & - \\ - & - \\ x_{n p 1} & x_{n p 2}\end{array}\right]$

Step 9: Calculate the losses for every particle by using load flow analysis for every generation.

Step 10: Investigate the minimum losses at every generation.

Step 11: Update the position of the searching agents with relevant equations.
Step 12: Adjust update positions with minimum and maximum constraints.

Step 13: Repeat the Step 3 to step 6 for all generations.

The flow chart for the proposed methodology is given in Fig. 3.

\section{Results and Discussion}

The proposed methodology is applied to the two test distribution systems which are IEEE 33 bus system and IEEE 69 bus system along with reconfiguration and DG placement at different scenarios with two different cases of each which is explained in the previous section. The results are presented is such a way that comparison table and figure between two cases with different scenarios.

\section{Test Case 1: IEEE 33 Bus Radial Distribution System}

The single line diagram of IEEE 33 bus radial distribution system is shown in the Fig. 4. There are three sub feeders at 2nd bus, 3 rd bus and 6th bus with 4buses, 3 three buses and 8 three buses respectively. The tie line switches are mentioned
Table 2 Real and reactive power losses at Scenario-1 and Scenario2

\begin{tabular}{llll}
\hline S.no & Scenarios & Reconfiguration Switches & Real and reactive power losses(kVA) \\
\hline 1 & Scenario-1 & 3334353637 & $202.76+$ i 135.24 \\
2 & Scenario-2 & 79143237 & $139.56+$ i 102.40 \\
\hline
\end{tabular}




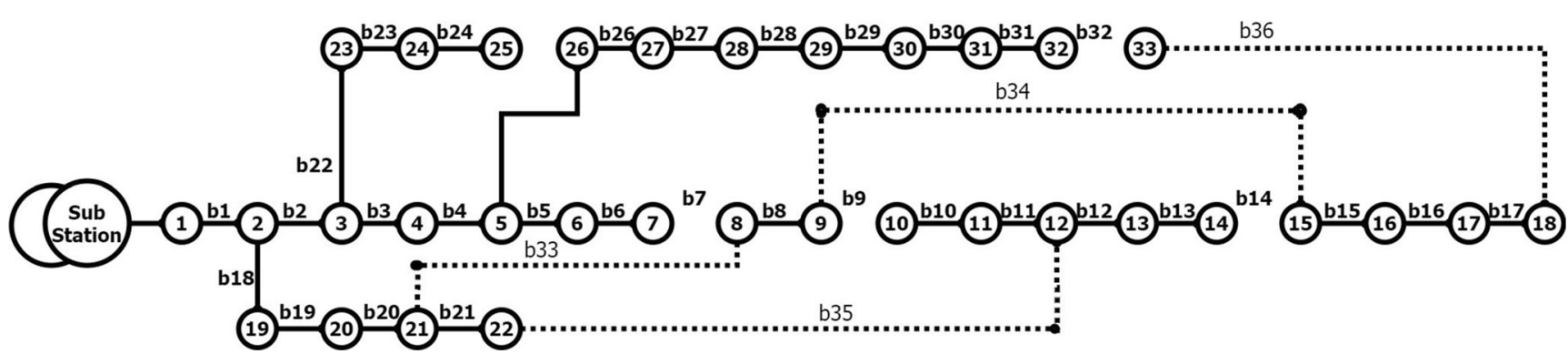

Fig. 5 Reconfiguration of IEEE 33 bus system at scenario 2

with dotted lines and the main line switches are denoted with solid lines.

The number of tie line switches of the distribution system are depends upon the number of loops of the system. By considering the Fig. 1, the number loops can be observed among solid line and dotted lines. The methodology for the two cases is applied separately to the test system. The bus voltage of the IEEE 33 bus radial distribution system without reconfiguration and DGs are shown in the Table 1 . The real power losses at the base case are $202.76 \mathrm{~kW}$ and reactive power losses are $135.24 \mathrm{kVar}$. The minimum voltage is 0.918 P.U at 18 th bus. The concept of reconfiguration is applied to IEEE 33 bus system with DA algorithm and the voltage profile of the system with only reconfiguration is given in Table 1 . The real and reactive power losses with reconfiguration are shown $139.56 \mathrm{~kW}$ and $102.40 \mathrm{kVar}$. The minimum voltage is 0.9378 p.u at the $32 \mathrm{nd}$ bus. By applying the methodology of third scenario i,e only Type 1 DG. The process of placing Type I DGs, such a way that the placements are increased and will stop by increasing the losses. The real losses of the system is reduced from $202.76 \mathrm{~kW}$ to $118.75 \mathrm{~kW}$ and reactive power losses are reduced from $135.24 \mathrm{kVar}$ to 83.69
KVar for optimal placing of DG at 29th bus with the size of $830 \mathrm{~kW}$ by using DA-PSO. The DA is used to select the location and PSO is used to calculate the optimal size. The further procedure is increasing of the placements of DG until the losses are affected. The Variation of losses for all the cases is shown in the Table 3. The losses and reconfiguration without DGs are separately mentioned in the Table 2.The same methodology is applied to another scenario i,e placement of DGs after the reconfiguration by using DA-PSO. The DA is used to select the optimal configuration and PSO is used to calculate the sizes and placements of the DGs (Fig. 5, 6 and 7). The comparative analysis of losses and voltage profiles at all scenarios of the IEEE 33 bus radial distribution is shown in the Fig. 8 and Table 3. The variation in real and reactive power losses are shown in Fig. 9 and Fig. 10.

\section{Test Case 2: IEEE 69 Bus Radial Distribution System}

The single line diagram of IEEE 69 bus system along with tie line switches is shown in the Fig. 11. The system has seven sub feeders which are at 3rd bus, 4th bus, 8th bus, 9th bus, 11 th bus and 12 th bus. The number of buses connected to the
Fig. 6 Single line diagram of IEEE 33 bus radial distribution system along with the Three DGs

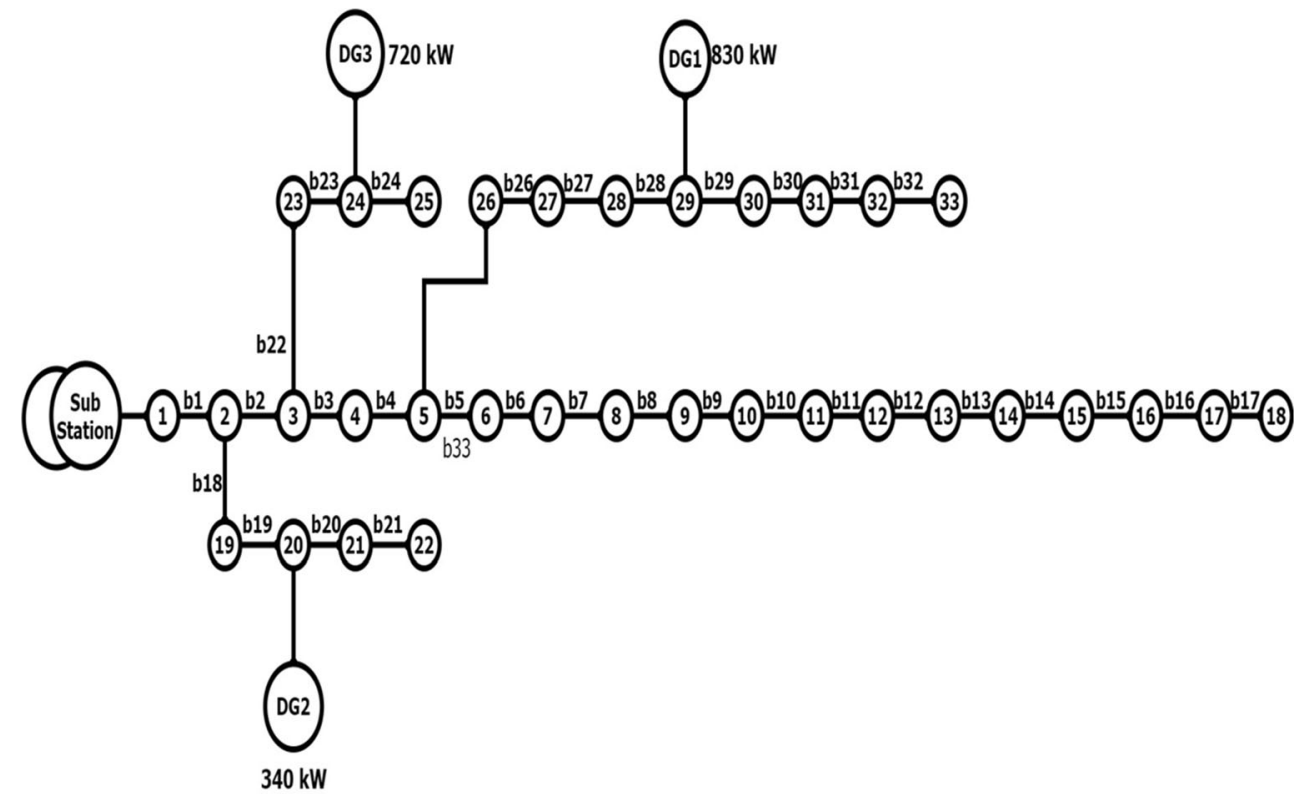




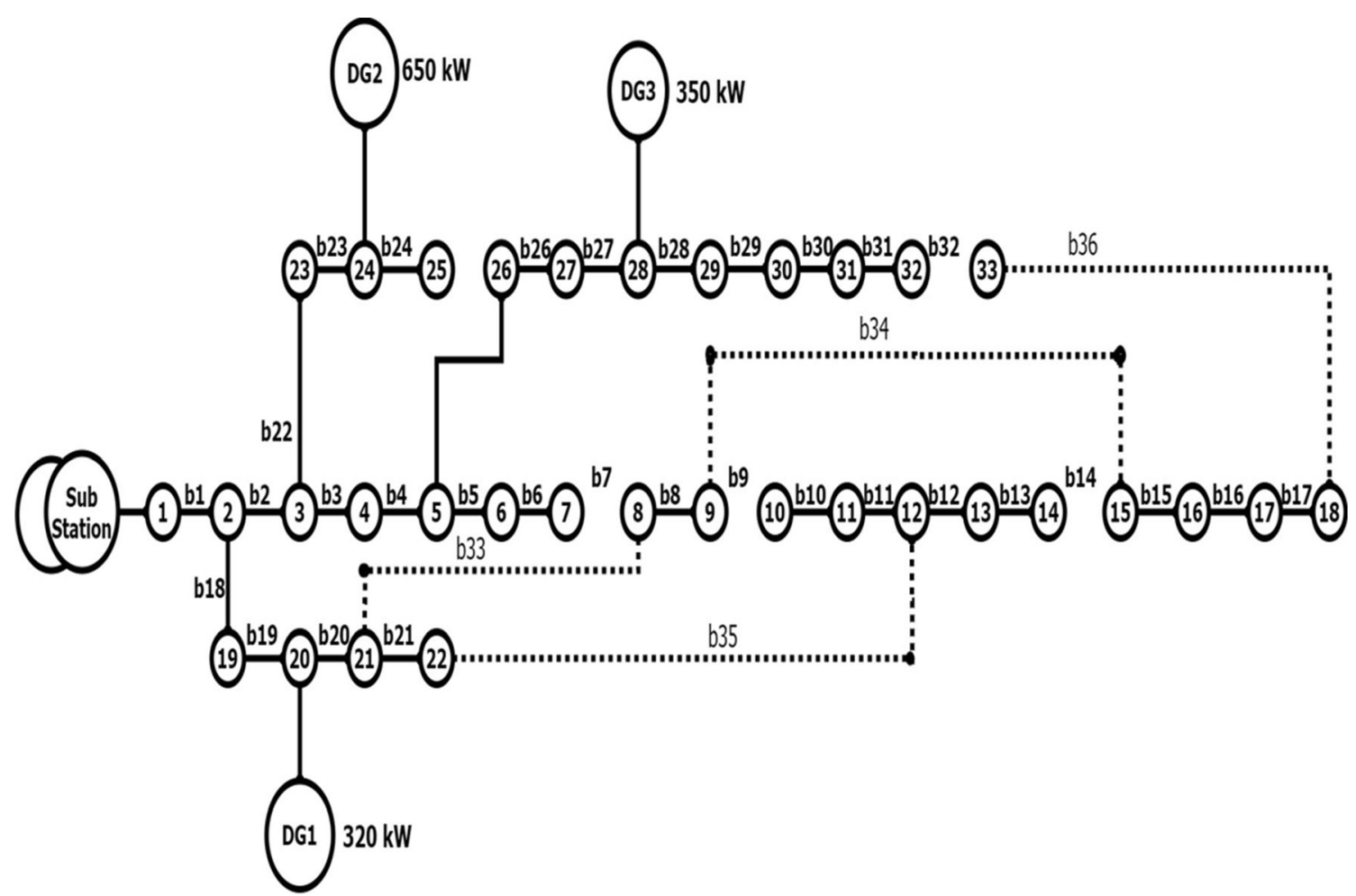

Fig. 7 Single line diagram of IEEE 33 bus radial distribution system along with the Three DGs after reconfiguration

Fig. 8 Comparative analysis of Voltage profile of IEEE 33 bus system of all scenarios

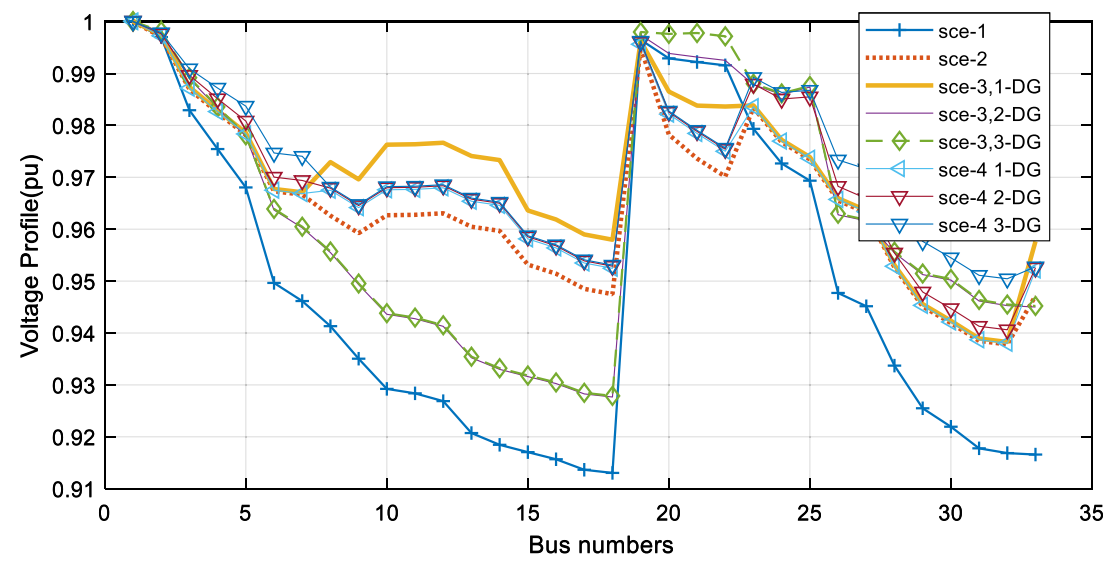

Table 3 Real and reactive power losses at Scenario 3 and Scenario 4

\begin{tabular}{|c|c|c|c|c|c|c|}
\hline S.No & Scenarios & Size of the DG & $\begin{array}{l}\text { Reconfiguration } \\
\text { switches }\end{array}$ & $\begin{array}{l}\text { Losses with } \\
\text { Placement } \\
\text { of one DG(KVA) }\end{array}$ & $\begin{array}{l}\text { Losses with } \\
\text { Placement } \\
\text { of two DGs(KVA) }\end{array}$ & $\begin{array}{l}\text { Losses with } \\
\text { Placement } \\
\text { of three DGs(KVA) }\end{array}$ \\
\hline 1 & Scenario-3 & $\begin{array}{l}830 \mathrm{~kW}(29) \\
830 \mathrm{~kW}(29), 340 \mathrm{~kW}(24) \\
830 \mathrm{~kW}(29), 340 \mathrm{~kW}(24) \text { and } \\
720 \mathrm{~kW}(20)\end{array}$ & & $\begin{array}{l}135.44+83.69 \mathrm{i} \\
- \\
-\end{array}$ & $\begin{array}{l}- \\
118.40+81.6 \mathrm{i} \\
-\end{array}$ & $\begin{array}{l}- \\
- \\
116.7+80.44 \mathrm{i}\end{array}$ \\
\hline 2 & Scenario-4 & $\begin{array}{l}340 \mathrm{~kW}(20) \\
340 \mathrm{~kW}(20), 650 \mathrm{~kW}(24) \\
340 \mathrm{~kW}(20), 650 \mathrm{~kW}(24) \text { and } \\
\quad 320 \mathrm{~kW}(28)\end{array}$ & & $\begin{array}{l}128.06+92.09 i \\
- \\
-\end{array}$ & $\begin{array}{l}- \\
109.57+80.8 \mathrm{i} \\
-\end{array}$ & $\begin{array}{l}- \\
- \\
91.26+68.4 \mathrm{i}\end{array}$ \\
\hline
\end{tabular}


Fig. 9 Real power losses at all scenarios and cases

Fig. 10 Reactive power losses at all scenarios and cases
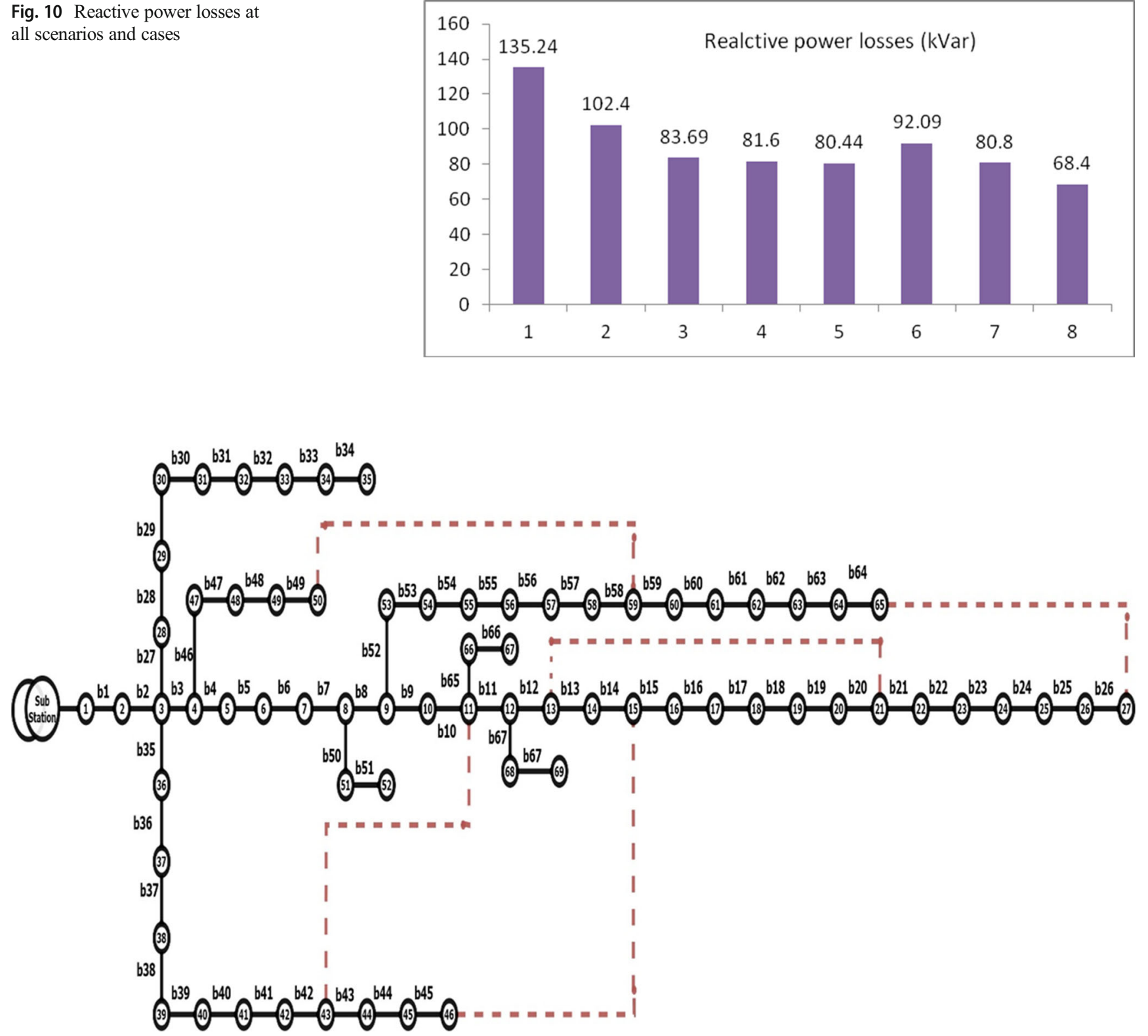

Fig. 11 Single line diagram of IEEE 69 bus system along with tie line switches 


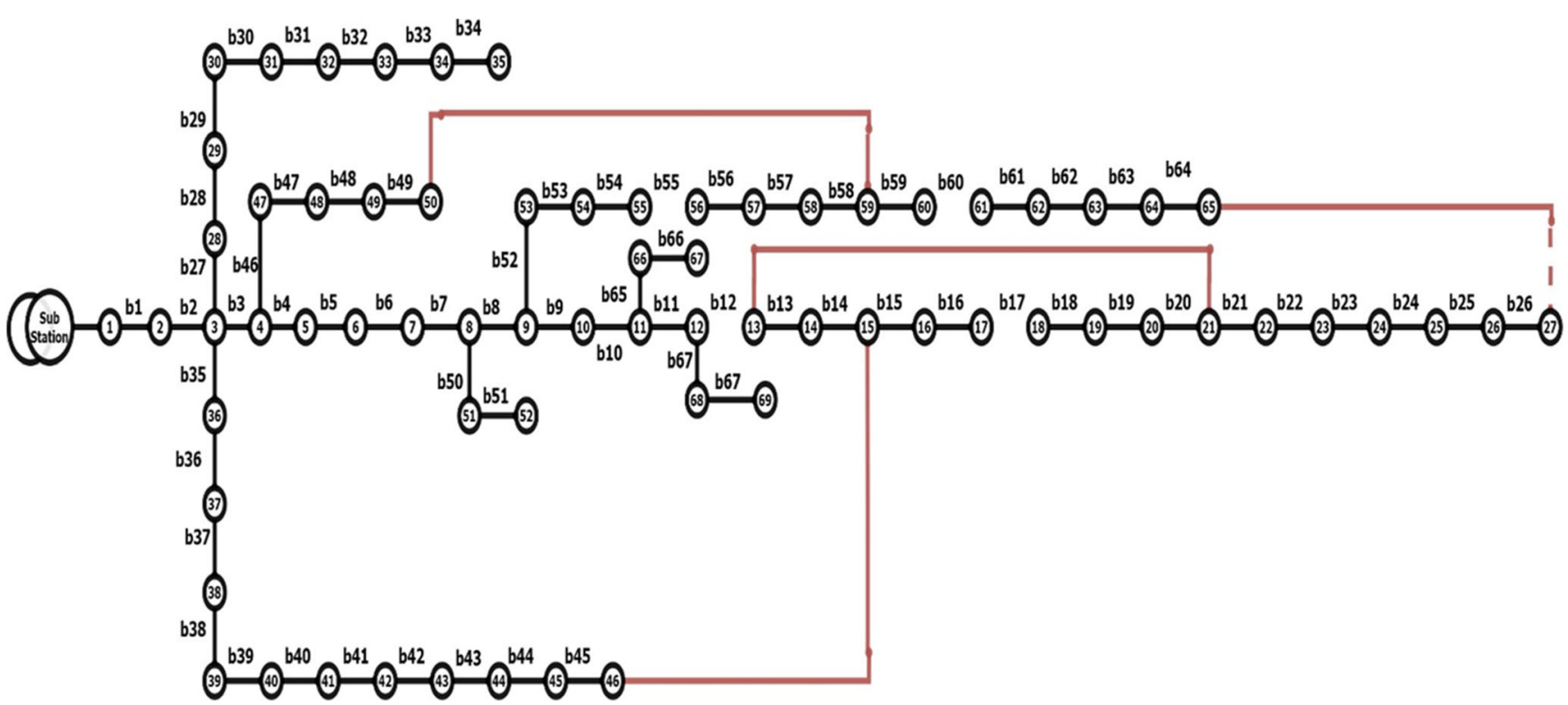

Fig. 12 Single line diagram of IEEE 69 bus system along with reconfiguration

Table 4 Real and Reactive power losses at Scenario-1 and Scenario-2

\begin{tabular}{llll}
\hline S.no & Scenarios & Reconfiguration Switches & Real and reactive power losses(kVA) \\
\hline 1 & Scenario-1 & 6970717273 & $225+\mathrm{i} 122.16$ \\
2 & Scenario-2 & 6913185661 & $105.35+\mathrm{i} 115.23$ \\
\hline
\end{tabular}

sub feeders are 6 buses, 7 buses, 4 buses, 2 buses, 13 buses, 2 buses and 2 buses. The procedure which is followed in 33 bus system is also applied to this system as well.

Figure 12 Shows the single line diagram of the IEEE 69 bus radial distribution system along with optimal reconfiguration. The loads are equally distributed to the main substation and losses are reduced from $225 \mathrm{~kW}$ to $105.35 \mathrm{~kW}$ and reactive power losses are reduced from $122.16 \mathrm{Kvar}$ to 115.23 kvar. The further detail of the system which is applying the proposed methodology is shown in the Table 4 and Table 5. The Fig. 13 and Figs. 14, 15, 16 and 17 are detailed the placement of DG and their sizes by using hybrid optimization technique

\section{Conclusions}

The losses in the radial distribution system will be reduced substantially by using DGs and reconfiguration system. The important thing we observed is that the losses are greatly reduced at scenario -4 with lesser overall size of DGs. The load is equally balanced by affecting both

Table 5 Real and Reactive power losses at scenario 3 and Scenario 4

\begin{tabular}{|c|c|c|c|c|c|}
\hline S.No & Scenarios & Size of the DG & $\begin{array}{l}\text { Losses with Placement } \\
\text { of one DG(KVA) }\end{array}$ & $\begin{array}{l}\text { Losses with Placement } \\
\text { of two DGs(KVA) }\end{array}$ & $\begin{array}{l}\text { Losses with Placement } \\
\text { of three DGs(KVA) }\end{array}$ \\
\hline \multirow[t]{3}{*}{1} & Scenario-3 & 300 kW (63) & $180.25+\mathrm{i} 87.0315$ & & \\
\hline & & 300 kW (63), 200 kW (20) & & $168.57+\mathrm{i} 81.57$ & \\
\hline & & $300 \mathrm{~kW}(63), 200 \mathrm{~kW}(20)$ and $600 \mathrm{~kW}(48)$ & & & $167.11+\mathrm{i} 78.016$ \\
\hline \multirow[t]{3}{*}{2} & Scenario-4 & $1400 \mathrm{kw}(60)$ & $51.2+\mathrm{i} 54.41$ & & \\
\hline & & $1400 \mathrm{kw}(60), 52.8 \mathrm{~kW}(44)$ & & $50.5+\mathrm{j} 53.32$ & \\
\hline & & $1400 \mathrm{kw}(60), 52.8 \mathrm{~kW}(44)$ and $129.35 \mathrm{~kW}(20)$ & & & $48.23+\mathrm{j} 50.43$ \\
\hline
\end{tabular}




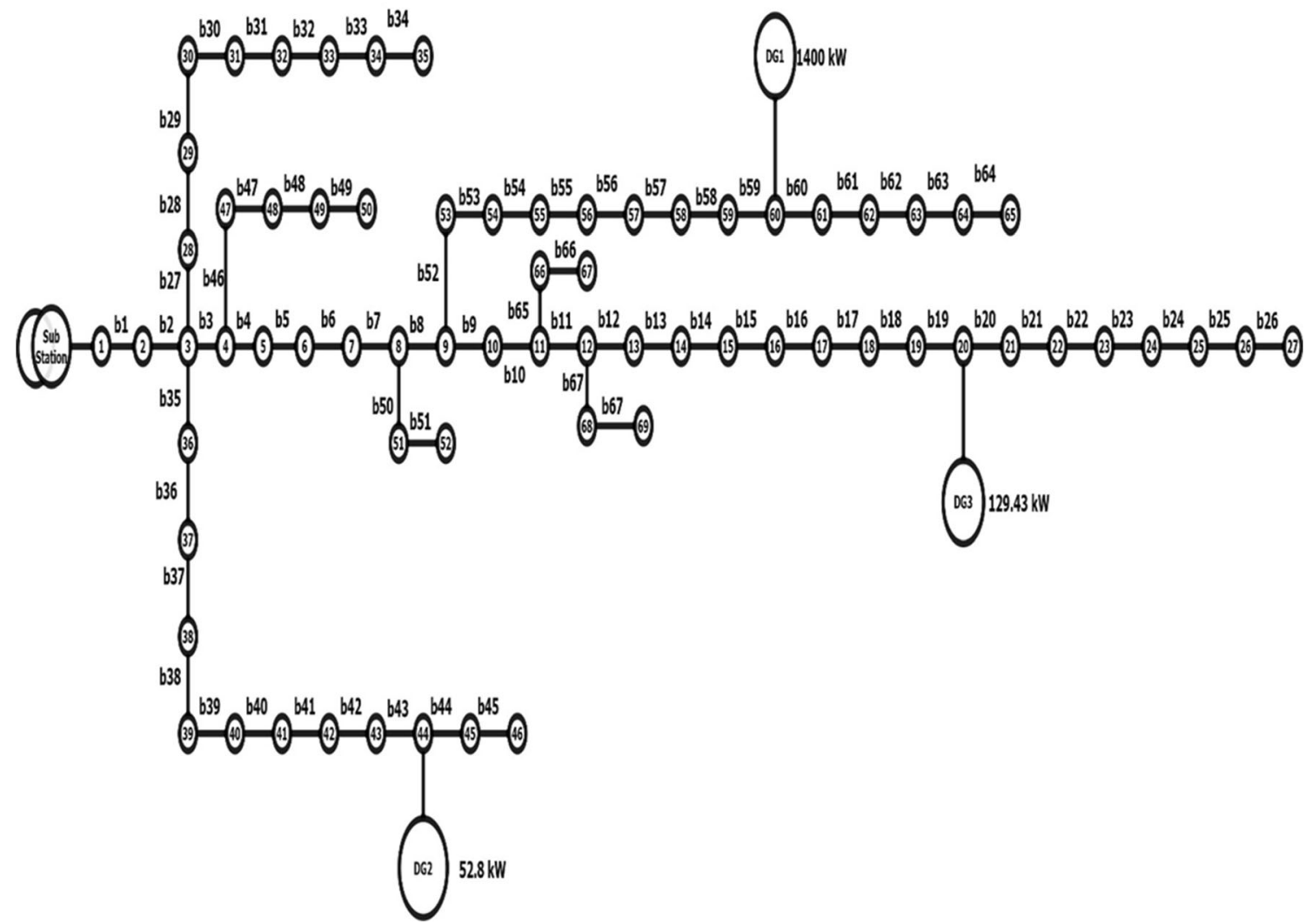

Fig. 13 Single line diagram of Optimized IEEE 69 bus radial distribution system for Scenario-3

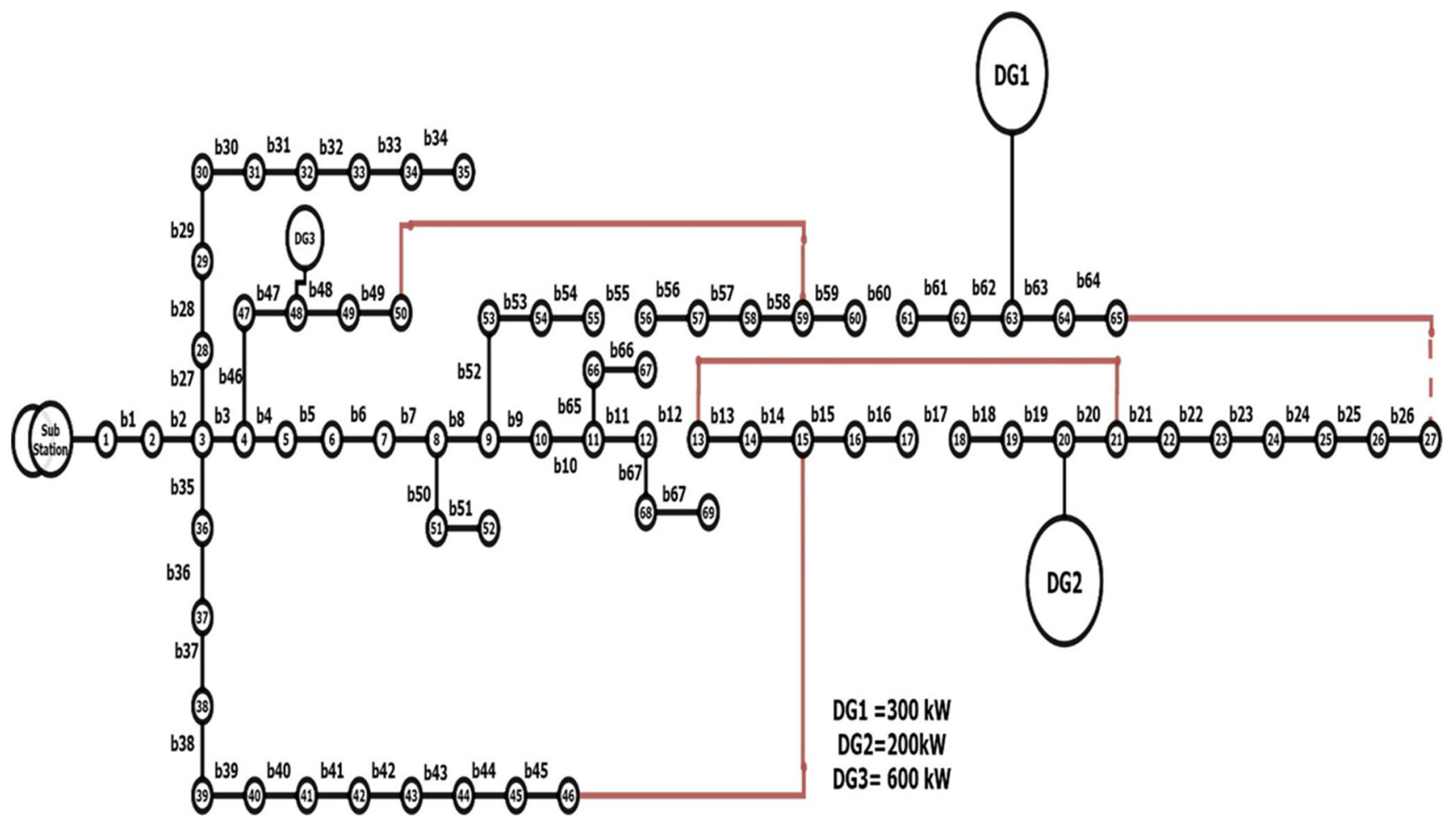

Fig. 14 Single line diagram of Optimized IEEE 69 bus radial distribution system for Scenario-4 
Fig. 15 Comparative analysis of Voltage profile of IEEE 69 bus system of all scenarios

Fig. 16 Real power losses at all scenarios and cases of IEEE 69 bus radial distribution system

Fig. 17 Reactive power losses at all scenarios and cases
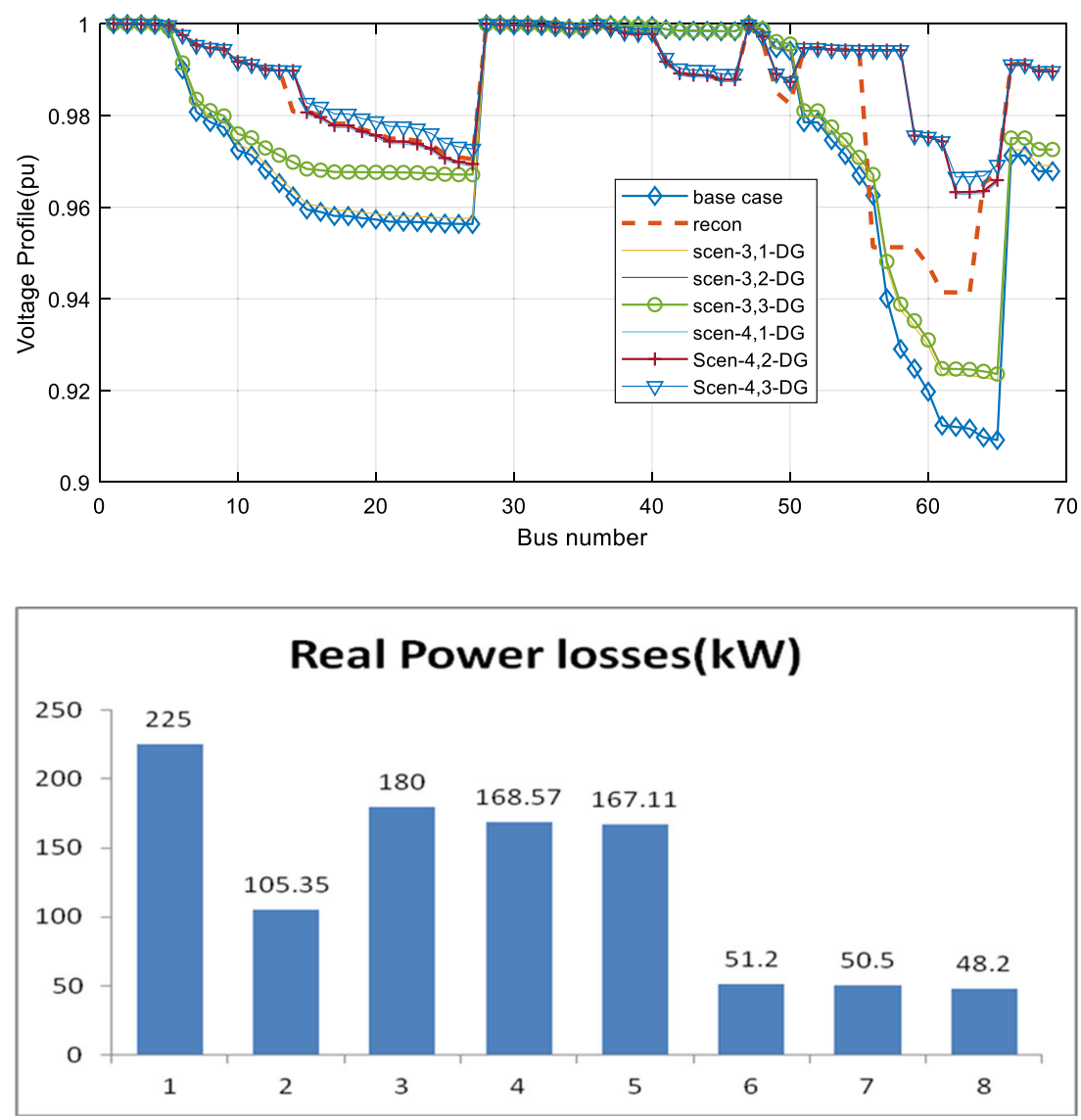

2. Salama MMA, Chikhani AY (1993) A simplified network

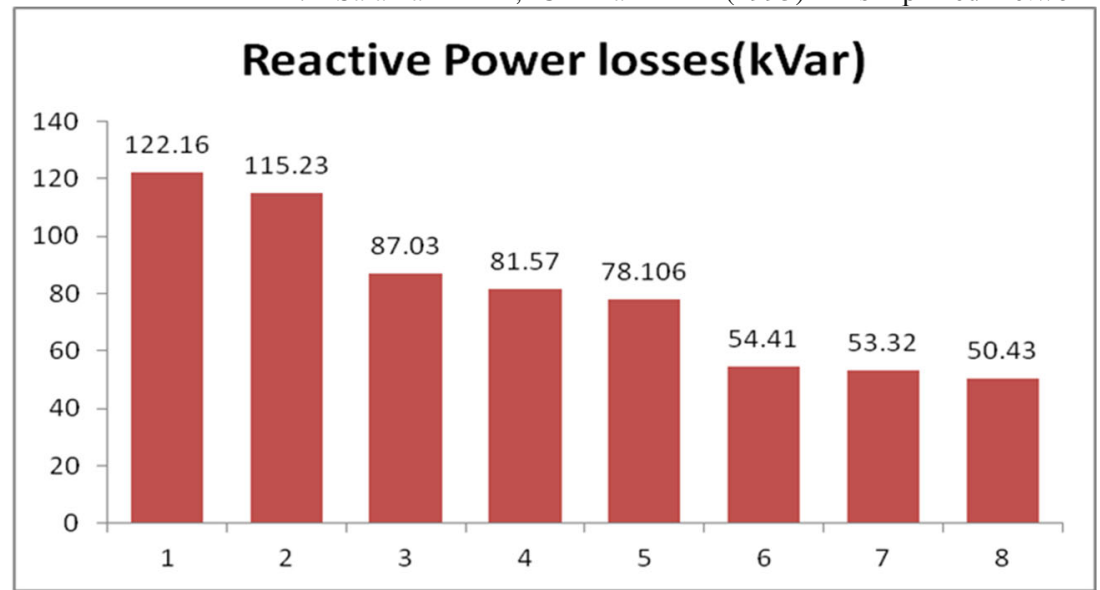

real and reactive power losses with increased system power factor. The reduction in the reactive power losses will be highly influenced on the voltage profile of the system. This is also proved in both the test cases of this paper.

\section{References}

1. Baran ME, Wu FF (April 1989) Network reconfiguration in distribution systems for loss reduction and load balancing. IEEE Transactions on Power Delivery 4(2):1401-1407 approach to the VAR control problem for radial distribution systems. IEEE Transaction on Power Delivery 8(3):15291535

3. Wagner TP, Chikhani AY, Hackam R (Oct. 1991) Feeder reconfiguration for loss reduction: an application of distribution automation. IEEE Trans Power Del 6(4):1922-1931

4. Chen TH, Chen MS, Hwang KJ, Kotas P, Chebli EA (July 1991) Distribution system power flow analysis-a rigid approach. IEEE Transactions on Power Delivery 6(3):1146-1153

5. Ghosh S, Sherpa KS (2008) An efficient method for load-flow solution of radial distribution networks. Int J Elect Power Energy Syst Eng 1(2):108-115 
6. Badran O, Mekhilef S, Mokhlis H, Dahalan W (June 2017) Optimal reconfiguration of distribution system connected with distributed generations : a review of different methodologies. Renewable and Sustainable Energy Reviews Volume 73:854-867

7. Duan D-L, Ling X-D (January 2015) Xiao-Yue Wu and bin Zhong "reconfiguration of distribution network for loss reduction and reliability improvement based on an enhanced genetic algorithm" international journal of electrical power and electrical energy. Volume 64:88-95

8. A.V. Sudhakara Reddy and M. Damodar Reddy "Optimization of network reconfiguration by using Particle swarm optimization" 16 February 2017, 2016 IEEE 1st International Conference on Power Electronics, Intelligent Control and Energy Systems (ICPEICES)

9. A.V. Sudhakara Reddy and M. Damodar Reddy "Network Reconfiguration of Distribution System for Loss Reduction Using GWO Algorithm" Vol. 7, No. 6, December 2017, pp. 3226 3234

10. D.B Prakash and C. Lakshminarayana "Optimal Siting of capacitors in radial distribution network using whale Optimization Algorithm" Alexandria Engineering Journal, Volume 56, Issue 4, December 2017, Pages 499-509
11. Mirjalili S, Lewis A (2016) The whale optimization. Adv Eng Softw 95:51-67

12. "Coordinated active power curtailment of grid connected PV inverters for overvoltage prevention." IEEE Transactions on Sustainable Energy 2.2 (2010): 139-147

13. "Coordinated control of distributed energy-storage systems for voltage regulation in distribution networks." IEEE transactions on power delivery 31.3 (2015): 1132-1141

14. "Inverter-based voltage control of distribution networks: a threelevel coordinated method and power hardware-in-the-loop validation." IEEE Transactions on Sustainable Energy (2019)

15. Zhang D, Zhang T, Xu X, Zhou Y, Zhang X (2017) Optimal reconfiguration of the active distribution network with distributed generation and electric vehicle. The Journal of Engineering 2017(13):1453-1456

Publisher's Note Springer Nature remains neutral with regard to jurisdictional claims in published maps and institutional affiliations. 